\title{
Empirical Study on Consumer Purchase Intention for Remanufacture Product
}

\author{
Hua HAN and Qiao-Lun GU* \\ Tianjin University of Technology and Education, Tianjin, China \\ Email: ahan5673088@163.com, btuteguqiaolunlucy@163.com
}

Keywords: Remanufacturing, Howard-Sheth model, Involvement, Purchase intention.

\begin{abstract}
Based on Howard-Sheth model, this paper has constructed a mode to analysis the influence of attitude and involvement to purchase intention and the influence of stimulus factors to attitude and involvement. The author collected data by questionnaire survey. The authors examine the reliability and validity of questionnaire and verify notion mode by using SPSS19.0 and AMOS19.0 software. Draw conclusions: (1) Attitude and involvement have significant effect on consumer purchase intention; (2) Environmental protective and sales promotion have significant effect on attitude and involvement; (3) Perceived price do not have significant impact on the attitude and involvement.
\end{abstract}

\section{Introduction}

Remanufacturing plays an important role in the aspect of protecting environment and saving resources [1]. Boosting the diffusion of remanufacture products benefits to alleviate the problem of energy and environmental. The remanufacturing was listed as important project in the national "13th Five-Year" plan. In the market, the proliferation of remanufacture products depends on the enterprise, policy support, and consumer purchase intention. But, there are little researches about consumer purchase intention for remanufacturing products, especially lack empirical research. Hongjiao Liu just describes simple data analysis about college students purchase behavior for remanufacture products, there was not theoretical mode [2]. Hutchensd research has been more than 20 years, with the gradual change of the economic and social value, consumer value orientation also have changed.

Based on the Howard-Sheth model, this paper have constructed the concept mode to analyze external factors influence on attitude and involvement and the impact of stimulating factors and internal factors to consumer purchase intention.

\section{Theoretical Model and Research Hypothesis}

\section{The Influence of Attitude on Purchase Intention}

Consumer purchase intention is affected by many factors, attitude is one of them. Ajzen has pointed out that attitude influence intention [3]. Guomeng Wang has proved environmental attitude has positive effection on green purchase behavior by empirical researching green purchasing behavior [4].

According to the Theory of Planned Behavior, consumer attitude have significantly predictive power to purchase intention. With the social progress and increasingly serious pollution of environment, consumer awareness of environmental protection increased gradually. Therefore, attitude treated as the leading factor of purchase intention are able to interpret and predict purchase intention. Put forward the following hypothesis:

H1: consumer attitude to remanufacturing products is positive influence to their purchase intention.

\section{The Influence of Involvement Level on Purchase Intention}

Many scholars concluded that the degree of consumer involvement affect their purchase intention. 
The empirical analysis of Ying Wang shows that for remanufacture products, perceived risk and involvement have a significant impact on consumer purchase intention [5]. The research of Jikun Huang shows that the more GM technology they know, the more willingness of accepting and buying GM foods consumers have [6].

Generally speaking, the higher degree of involvement, the more time and energy consumers spent on choice and decisions before purchase [7]. For remanufacture products, the degree of consumer involvement affects attitude and decisions. This paper argues that the degree of involvement has an impact on purchase intention, put forward hypothesis:

H2: the degree of involvement has significantly positive impact on purchase intention.

\section{The Effect of External Stimulus on Intrinsic Variable}

Howard - Sheth mode was proposed in 1963 by the scholar Howard, the official formation was revised in 1969 by cooperate with Sheth [8]. He considers consumer behavior could be thought from four aspects: stimulus or input factors (input variables), external factors, internal factors (internal process), reflecting or output factor.

Therefore, the article selected sale promotion and perceived price and environmental protection as stimulating factor, selected attitude and involvement as internal factors, selected purchase intention as the output factor. It is assumed that the internal factors are affected by external stimuli according to the Howard - Sheth model. Put forward hypothesis:

H3a1/H3a2: the environmental protection has significantly positive impact on attitude and involvement.

H3b1/H3b2: perceived price advantage have significantly positive impact on attitude and involvement.

H3c1/H3c2: sales promotion has significant positive impact on attitude and involvement.

The conceptual mode is shown in Figure 1.

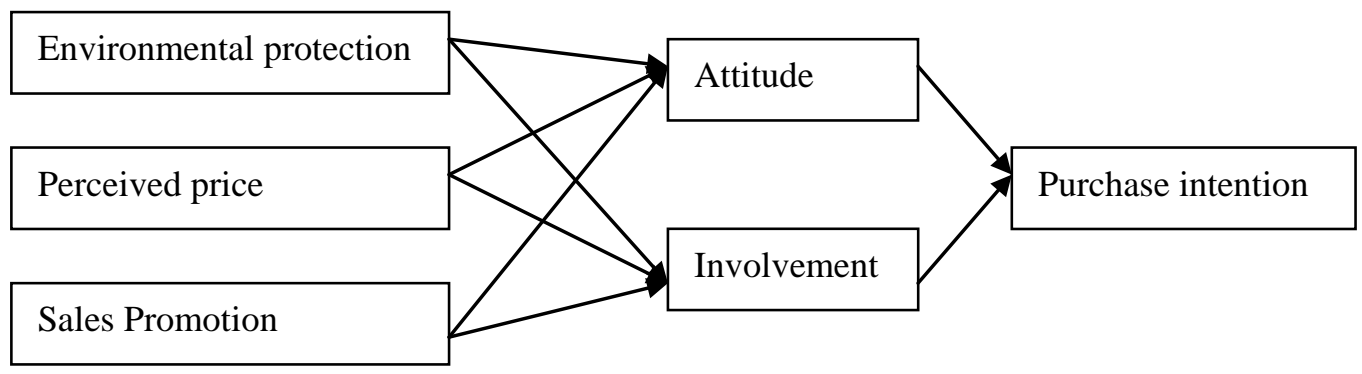

Figure.1 Conceptual Mode

\section{Research Design and Data Collection}

\section{Questionnaire Design}

In the form of five point measurement of the Likert, author selected the number of 1 to 5 , which indicates "very do not agree" to "very agree". Questionnaire should be responded based on individual subjective thinking.

\section{Data Collection}

The questionnaire is separated two parts, include paper questionnaire and network questionnaire. It takes a month from pre-test to record all data. The total of questionnaire is 295, there are 249 valid questionnaires. The effective rate of recovery is $84.4 \%$. In this section, we use the method of descriptive statistics to analyze the data of questionnaire. The basic consumer characteristics are shown in table 1. 


\section{Data Analysis and Hypothesis Testing}

\section{Reliability and Validity Test}

This study used the SPSS19.0 software, selected Cronbach's $\alpha$ to mea sure reliability of the questionnaire, got results: the three Cronbach's $\alpha$ of involvement attitude and purchase intention is $0.739,0.840,0.832$. The three Crownbach's $\alpha$ of environmental protection and perceived price advantage and promotion are 0.835, 0.747, 0.762. Based on other scholar research, Minglong Wu said it is very good that the reliability coefficient is more than 0.8 , and it can be accepted between 0.8 and 0.7 . Therefore, the questionnaire reliability can be accepted.

Table 1 statistical characteristics

\begin{tabular}{llll}
\hline \multicolumn{2}{c}{ Sample feature description } & Frequency & Percentage (\%) \\
\hline \multirow{4}{*}{ Gender } & Male & 110 & 44.2 \\
\multirow{4}{*}{ Age } & Female & 139 & 55.8 \\
& 25 below & 75 & 30.1 \\
& $26-31$ & 79 & 31.7 \\
& $32-36$ & 66 & 26.5 \\
& 37-40 & 18 & 7.2 \\
& More than 41 & 11 & 4.4 \\
\hline
\end{tabular}

In this study, the KMO of the sample data is 0.868 , which is more than standard value 0.5 . The significant level of $\mathrm{P}$ is less than 0.01 , which reached significant level. The sample is fit for condition of factor analysis. This paper used factor analysis method to analyse data, used maximum variance method. The rotated factor modulus are shown in table 2a, table $2 \mathrm{~b}$.

Table 2a rotational factor loading matrix

\begin{tabular}{|c|c|c|c|}
\hline Observable Variable & \multicolumn{3}{|c|}{ Factor Loading Value } \\
\hline & 1 & 2 & 3 \\
\hline Attitude & .874 & & \\
\hline Attitude & .787 & & \\
\hline Attitude & .735 & & \\
\hline Purchase intention PI1 & & .825 & \\
\hline Purchase intention PI2 & & .795 & \\
\hline Purchase intention PI3 & & 689 & \\
\hline Involvement ID1 & & & .850 \\
\hline Involvement ID2 & & & .729 \\
\hline Involvement ID3 & & & 669 \\
\hline
\end{tabular}

Table $2 \mathrm{~b}$ rotational factor loading matrix

\begin{tabular}{llcc}
\hline \multicolumn{1}{c}{ Observable Variable } & \multicolumn{3}{c}{ Factor Loading Value } \\
\hline & 1 & 2 & 3 \\
Environmental protection E1 & .873 & & \\
Environmental protection E2 & .857 & & \\
Environmental protection E3 & .824 & & \\
Sales promotion SP1 & & .829 & \\
Sales promotion SP2 & & .796 & \\
Sales promotion SP3 & & .750 & \\
Perceived price P1 & & & .879 \\
Perceived price P2 & & & .862 \\
\hline
\end{tabular}


This paper extracted three intrinsic variables, the cumulative variance contribution rate was 72.833\%, extracted three extrinsic variables, cumulative variance contribution rate was $75.103 \%$. The factor load is more than 0.6 after rotation, which indicate that the questionnaire have good convergent validity. There are some indexes in certain common factor is greatest in all common factors, which indicates that the questionnaire has good discriminative validity.

\section{Mode Validation and Results Analysis}

This paper used AMOS19.0 software to verify the conceptual mode and hypothesis, the test results are shown in table 3.

The result shows that the path coefficient of consumer attitudes to purchase intention is 0.483 ( $\mathrm{P}$ $<0.01$ ), indicates that there are positive impact from attitude to purchase intention, hypothesis HI is founded. The path coefficient of consumer involvement to purchase intention is $0.389(\mathrm{P}<0.01)$, which indicates that there is a positive impact from involvement to purchase intention, hypothesis H2 was founded.

In addition, sales promotion and environmental protection have significant positive impact on involvement and attitude, hypothesis H3c1, H3c2, H3a1, H3a2 are verified. The path coefficient of perceived price to attitudes and involvement are negative and did not reach a significant level, it is not conform to original hypothesis. H3b2, H3b1 was rejected.

Table 3 hypothesis validation results

\begin{tabular}{llll}
\hline \multicolumn{1}{c}{ Hypothesis } & Std. Estimate & $\mathrm{P}$ & Conclusion \\
\hline H1: Attitude to purchase intentions & 0.483 & $* * *$ & Support \\
H2: Involvement to purchase intention & 0.389 & $* * *$ & Support \\
H3a1: Environmental protection to attitude & 0.422 & $* * *$ & Support \\
H3a2: Environmental protection to involvement & 0.215 & 0.005 & Support \\
H3b1: Perceived price to attitude & -0.115 & 0.238 & Opposite \\
H3b1: Perceived price to involvement & -0.129 & 0.232 & Opposite \\
H3c1: Sales promotion to attitude & 0.527 & $* * *$ & Support \\
H3c2: Sales promotion to involvement & 0.728 & $* * *$ & Support \\
\hline
\end{tabular}

Note: $* * *$ indicates that the path coefficient is significant at the 0.01 level.

The fitness index is evaluated to assess whether path analysis mode match data, it reflects accordance between hypothesis and actual data. Mengqing Sui believes that it is imperfect that using one fitting index to assess the goodness of fit of the mode. So this article takes GFI, AGFI, RMSEA, IFI, CFI to evaluate the concept mode.

The results are shown in table 4 by using AMOS19.0 software. We can conclude that conceptual mode accord to data through comparing the standard value with the actual value, the data support hypothesis.

Table 4 fitting index

\begin{tabular}{lccclcc}
\hline Fitting Index & $\chi^{2} / \mathrm{df}$ & GFI & AGFI & RMSEA & IFI & CFI \\
\hline Actual Value & 1.898 & 0.910 & 0.872 & 0.060 & 0.950 & 0.949 \\
Standard Value & $<3$ & $>0.9$ & $>0.8$ & $<0.08$ & $>0.9$ & $>0.9$ \\
\hline
\end{tabular}

\section{Results Discussion}

\section{(1) The Impact of Consumer Attitudes to Purchase Intention}

The path coefficient of attitude to purchase intention is 0.483 , C.R. value is 5.942 , it is significant at the level of 0.01. This indicates that there is a positive impact from attitude to purchase intention, which means the more positive attitude of consumers toward remanufacturing products, the more 
remanufactured product they incline to buy is fit with actual situation. From the table 3, it can be seen that the influence of attitude to purchase intention is greater than involvement.

Attitude is affected by sales promotion and environmental protection. By analyzing the table 3, the impact of sales promotion to attitude is the biggest, followed by the environmental protection, which is consistent with the reality that the mall stimulates consumer willingness of buying by a variety of advertising and promotion. Perceived price has negative effect on consumer attitude, and it is not significant, which indicates that perceived price has inconspicuous impact to consumer attitude.

\section{(2) The influence of involvement to purchase intention}

In the table 3, the path coefficient of involvement to purchase intention reached significant level of $0.01, \mathrm{~T}$ value is 4.620 , path coefficient is 0.389 . There is positive impact from involvement to purchase intention. It means that the higher degree of involvement about remanufacture product, the higher degree of attention, the stronger intention they purchase.

Involvement is affected by product knowledge level and sales promotion, environmental protection character of remanufacture product boost consumers to understand the relevant information of remanufacture products. Table 3 shows that path coefficient of sales promotion to involvement is very large, which means promotion have an important impact on consumer involvement.

\section{Conclusions and Recommendations}

In this study, this paper regarded attitude have positive impact on purchase intention, involvement have same impact. This study selected sales promotion, perceived price, environmental protection as external variables. The results show that external variables have some influence on purchase intention. I hope results have referenced significance for the future research.

For government, they should provide policy support to create favorable legal environment, provide promotional support, promote environmental awareness.

For remanufacture enterprises and related industries, they should enhance the remanufacture product quality, enhance consumer perception for product quality, announce product information, earnestly fulfill service commitments, perfect customer service system and establish remanufacture product experience activities, improve the involvement of consumers for remanufacture product.

\section{Acknowledgement}

This work was supported by Humanity and Social Science Planning Foundation of Ministry of Education of China (15YJA630018).

\section{Reference}

[1]B.S. Xu. Prospects and developing of remanufacture forming technology. J Mech Eng. 15(2012)96-105.

[2]H.J. Liu, L. Liang. Study on consumers' awareness and purchase behavior of remanufactured products in China. Oper Res Mange Sci. 18(2009)159-163.

[3]Ajzen I. The theory of planned behavior. Organ Behav Hum Dec. 50(1991)179-211.

[4]G.M. Wang. An empirical analysis of the relationship between personal value, environmental attitude and consumer's green purchasing behavior. Soft Sci. 4(2010):135-140.

[5]Y. Wang, Y. Li. An empirical research on the consumer's purchase intention of new energy vehicles based on perceived risk and involvement. J Appl Stat Manage. 32(2013)863-872.

[6]J.K. Huang, H.G. Chou, J.F. Bai, C. Pray. Awareness, acceptance and willingness to buy genetically modified foods in urban China. Soft Sci. 24(2010)135-140. 
[7]S.E. Beatty, S.M. Smith. External search effort: An investigation across several product categories. J Consum Res. 14(1987)83-95.

[8] J.A. Howard, J.N Sheth. The theory of buyer behavior. J Am Stat Assoc. 1969. 